\title{
Management and endovascular therapy of ureteroarterial fistulas: experience from a single center and review of the literature
}

\author{
Bjoern Simon ${ }^{1 *}$ DD, Jakob Neubauer ${ }^{1}$, Martin Schoenthaler ${ }^{2}$, Simon Hein ${ }^{2}$, Fabian Bamberg ${ }^{1}$ and Lars Maruschke ${ }^{1,3}$
}

\begin{abstract}
Background: Ureteroarterial fistula (UAF) is a rare but potentially life threatening disease. The aim of this study was to evaluate the outcome of endovascular therapy for UAF treatment.

Methods: This retrospective case series evaluates a single center experience of percutaneous stent graft (SG) angioplasty and/or coil embolization for UAF. Patient follow-up included technical and early clinical success, complications and revisional procedures. We also conducted a systematic review of the literature reporting on endovascular UAF management.

Results: We identified 17 UAF in 16 patients (12 male, 4 female, mean age $69.8 \pm 11.3$ years) who underwent endovascular UAF therapy at our tertiary hospital. All patients presented with hematuria. 5/17 (29.4\%) presented with flank pain, in 7 (41.2\%) cases patients were in hypovolemic shock. Risk factors of UAF included chronic indwelling ureteral stents in all fistulas, major pelvic surgery in 13 cases (76.5\%). In 6 cases (35.3\%) SG were placed from the common iliac artery (CIA) to the external iliac artery (EIA) following coil embolization of the proximal internal iliac artery (IIA). SG placement without previous coil embolization was performed in 10 fistulas (58.8\%). In one case only coil embolization of the IIA was performed. Mean follow-up was 654 (range: 1-3269) days. All procedures were technically successful and no procedure related deaths occurred during follow-up. During the initial hospital stay hematuria disappeared in 14/17 cases (82.4\%). Overall, four patients suffered recurrent hematuria, which in three cases resolved after a secondary intervention. One recurrent UAF related death occurred during follow-up 229 days after initial treatment.

A total of 152 UAF cases were additionally analyzed from our systematic literature review: SG placement with or without embolization was performed in 140 cases (92.1\%) while embolization alone was done in 12 cases (7.9\%). Complications included UAF recurrence (18/152, 11.8\%), SG thrombosis (7/140, 5\%), and SG infections (5/140, 3.6\%) with an overall complications rate of $13.8 \%$. Five patients died due to UAF (3.3\%).

Conclusion: Endovascular therapy offers high technical success rates and rapid bleeding control of UAF. Severe complications like SG occlusions or SG infections are rare but significant. Antibiotic treatment and single antiplatelet therapy improve SG durability as well as close and long follow-up to timely perform repeated endovascular or surgical treatment if necessary.

(Continued on next page)
\end{abstract}

\footnotetext{
* Correspondence: bjoern.simon@uniklinik-freiburg.de

'Department of Radiology, Medical Center - University of Freiburg, Faculty of Medicine, University of Freiburg, Freiburg, Germany

Full list of author information is available at the end of the article
}

\section{Springer Open}

(- The Author(s). 2021 Open Access This article is licensed under a Creative Commons Attribution 4.0 International License, which permits use, sharing, adaptation, distribution and reproduction in any medium or format, as long as you give appropriate credit to the original author(s) and the source, provide a link to the Creative Commons licence, and indicate if changes were made. The images or other third party material in this article are included in the article's Creative Commons licence, unless indicated otherwise in a credit line to the material. If material is not included in the article's Creative Commons licence and your intended use is not permitted by statutory regulation or exceeds the permitted use, you will need to obtain permission directly from the copyright holder. To view a copy of this licence, visit http://creativecommons.org/licenses/by/4.0/. 
(Continued from previous page)

Evidence-based medicine: Level 4, case series.

Keywords: Ureteroarterial fistula, Arterioureteral fistula, Endovascular therapy, Hematuria, Ureteral catheterization, Stent graft, Coil embolization

\section{Background}

Ureteroarterial fistula (UAF) is a rare but potentially life threatening clinical entity first described in 1908 by Moschcowitz (Moschcowitz, 1908). UAF is classified into primary (15\%) and secondary (85\%) lesions (Pillai et al., 2015). Primary fistulas are mainly seen in combination with aortoiliac aneurysmal disease. Secondary fistulas typically occur after pelvic surgery for malignancy with or without radiation therapy, or after vascular surgery with synthetic grafting (Bergqvist et al., 2001; Luther et al., 2014). The most common risk factor to develop an UAF is the presence of a chronic indwelling ureteral stent (Das et al., 2016). This is possibly due to the fact that mechanical fixation of the ureter triggers inflammation and fibrosis in the adjacent pulsating artery (Horie et al., 2019).

The most common location of UAF is the crossing of the distal left common iliac artery (CIA) and the ureter (Das et al., 2016; van den Bergh et al., 2009). The leading symptom is gross hematuria (Bergqvist et al., 2001; Das et al., 2016; Krambeck et al., 2005). UAF is a rare condition; however, since the increase in life expectancy in patients suffering of pelvic malignancies, this condition is observed more often (Das et al., 2016; Fox et al., 2011).

Different treatment options including surgery or surgery combined with transarterial embolization have been described (Fox et al., 2011; Krambeck et al., 2005; van den Bergh et al., 2009). More recently, stent graft (SG) placement has been reported as an effective alternative treatment; however, only small series using a variety of different, mostly self-expanding SG or iliac extensions from aortic bifurcation grafts have been reported (Fox et al., 2011; Guntau et al., 2017; Krambeck et al., 2005; Okada et al., 2013).

Thus, the purpose of the study was to evaluate the safety and effectiveness of endovascular therapy in UAF and to establish an interventional radiological therapy regime for these rare but critical cases.

\section{Methods}

IRB approval was obtained on June 25, 2020 by the institutional review board of the University of Freiburg (\#368/20).

We included all consecutive patients referred for endovascular therapy for UAF at our institution from November 2005 to March 2020. We reviewed patient characteristics, comorbidities, and clinical presentation from medical records. The clinical diagnosis of an UAF was based on pulsatile ureteral bleeding from either side on cystoscopy and/or in retrograde pyelogram by the referring urologist.

Radiological diagnostic work up included either contrastenhanced computed tomography (CECT), unenhanced computed tomography (UECT) or conventional angiography. CT was used to rule out renal hemorrhages and plan endovascular treatment. All patients underwent conventional catheter angiography. Angiographic procedures were performed under local anesthesia via a percutaneous transfemoral approach. Five French (Fr) angiographic sheaths were placed using Seldinger's technique. Angiograms were obtained with manual contrast injection via a $5 \mathrm{Fr}$ angiographic catheter. For SG placement, the $5 \mathrm{Fr}$ sheath was replaced by a larger sheath (7 Fr - 14 Fr) and an additional stiff wire was used. Most UAF were treated with percutaneous covered SG placement into the iliac axis covering the site of the fistula. In a minority of cases fistulas we performed an additional coil embolization of the internal iliac artery (IIA). Stent size was chosen to match the individual patient's anatomy. In one patient the bleeding site was localized in the IIA alone. In this case we treated the fistula by coil embolization of the IAA without SG placement. The procedure was considered complete and technically successful after a final angiogram confirmed the correct SG placement at the target location and/or the sufficient embolization of the IIA. Early clinical success was defined as freedom of hematuria in the current hospital stay. Patients were routinely followed at our outpatients clinic or by private urologists as all patients carry ureteral stents. Follow-up examinations are performed according to individual requirements (minor bleeding episodes, plugging of ureteral stents, hydronephrosis; usually 2 to 4 weeks after ureteral stent placement, followed by routine exams every 3 to 6 months). Follow-up examinations include urinalysis, urine culture, laboratory tests, and sonography. Periinterventional management included antibiotic treatment based on urine cultures and resistance profiles. Since all patients carried ureteral stents, we found no patient without bacterial colonization. Anticoagulation therapy was switched to low-molecular weight heparin equivalent to the patients'baseline anticoagulation dosage or prophylactic dosage. The decision for postinterventional anti-platelet therapy was implemented in consultation with the referring urologists and intensive care physicians. All but two patients were put on acetylic salicylic acid $100 \mathrm{mg} /$ day immediately following 
UAF treatment, 6 patients received prolonged dual antiplatelet regime of additional clopidogrel $75 \mathrm{mg} /$ day (12 weeks) and short-term dual antiplatelet therapy (clopidogrel $75 \mathrm{mg} /$ day for 6 weeks) in one case. One patient received 12 weeks of clopidogrel $75 \mathrm{mg} /$ day combined with previously started oral anticoagulation. The patient with coil embolization only did not receive any anti platelet therapy. A descriptive analysis was performed. Continuous data were summarised by median, arithmetic mean, and range. Categorical data were summarised by the total number of patients in each category. Relative frequencies are displayed as valid percentages.

We performed a literature search of the PubMed database using the following keywords: "ureteroarterial fistula", "arterioureteral fistula" and "uretero iliac fistula". We identified 55 articles published in English from January 2018 to March 2021. Studies were included if they presented data of adult patients regarding endovascular therapy, results on technical success, complications, and outcomes of UAF. Articles were excluded if they reported nonextractable data, UAF treatments other than endovascular, or were missing data on outcome or management of UAF. We also excluded systematic reviews, comment articles, or correspondence.

\section{Results}

In the study period, 17 endovascular UAF cases with a total of 16 patients from the author's hospital were analyzed.

Furthermore, we updated the comprehensive review by Subiela et al. (Subiela et al., 2018), who published a case series of their own patients and from a systematic literature review on articles regarding the endovascular management of UAF between 1990 and 2017. From the 55 identified articles through PubMed database research, we included only studies which were considered of interest and met the inclusion criteria. Finally, 15 articles were added to the review by Subiela et al. with a total of 152 UAF cases (Table 1).

\section{Clinical findings}

In the study period, 17 UAFs with a total of 16 predominantly male patients were included in the analysis $(75 \%$ male, mean age $69.8 \pm 11.3$ years). All patients presented with hematuria. Approximately one third of patients (31.3\%) exhibited additional flank pain, in seven cases (41.2\%) patients were in hypovolemic shock. In $94.1 \%$ of the cases patients presented with acute urinary retention. Half of the patients had chronic nephropathy. Risk factors of UAF included chronic indwelling ureteral stents in all fistulas, major pelvic surgery in 13 cases (76.5\%) and history of pelvic or genitourinary malignancies including colorectal cancer (10 cases), uterine/cervical cancer (3 cases), bladder cancer (1 case), testicular cancer (1 case) and prostate cancer (1 case). One patient had radiotherapy as primary treatment, one patient was under active surveillance and the only patient who did not suffer of a malignancy but of Ormond's disease had cortisone therapy as primary treatment. Fourteen of 15 patients with cancer had adjuvant radiation therapy and chemotherapy. Five patients (31.3\%) suffered of vasculopathies, two had severe claudication (Rutherford III), one had a right critical limb ischemia (Rutherford V), one had abdominal aortic aneurysmal disease and one patient had documented peripheral arterial occlusive disease with aortofemoral bypass. Patient characteristics are summarized in Table 2.

\section{Imaging}

Urologists were able to confirm signs of ureteral bleeding and correctly located the site of bleeding by using cystoscopy in all patients. In 10 cases the first radiological diagnosis was done by CECT, in 4 cases direct catheter angiography in readiness to intervene followed urological diagnosis confirmation, and in 3 cases an unenhanced CT was performed prior to angiography. CECT directly identified the fistula only in two cases (of 10 cases who received preinterventional CECT) with extravasation into the ureter. Angiography was positive in 3 of 17 cases. CT or angiography identified the crossing point between ureter and iliac artery in all patients. In 10 cases, the UAF was located at the CIA, in 3 cases each the IIA or the external iliac artery (EIA) was compromised respectively; in one exceptional case the fistula was located at the aortofemoral bypass graft.

\section{Procedures}

We inserted SG without previous coil embolization in 10 fistulas. In 6 cases we performed coil embolization of the proximal IIA prior to SG implantation. In one case the UAF was located solely in the IIA and was therefore treated by coil embolization alone. In three cases a secondary procedure was necessary due to recurrent bleeding during the hospital stay: In two cases SG extension and additional coil embolization of the IIA was needed and in one fistula IAA coiling alone was sufficient. Unrelated to the UAF but because of ongoing aneurysm growth due to aneurysmosis of the aortoiliac territory a secondary SG extension into the proximal CIA was required in one case.

Different types of balloon-expandable and self-expandable SG were used: Advanta V12 (Atrium Medical, $\mathrm{NH}, \mathrm{USA}$ ) in 7 cases, Fluency (Bard Peripheral Vascular, Tempe, AZ, USA) in 5, Gore Excluder endograft (Gore, Flagstaff, AZ, USA) in 3, Viabahn endograft (W. L. Gore, Flagstaff, AZ, USA) in 3 and Endurant II endograft (Medtronic Vascular, Santa Rosa, CA, USA) in 1. In 16 of 17 cases puncture site was closed by a closure device: In 4 


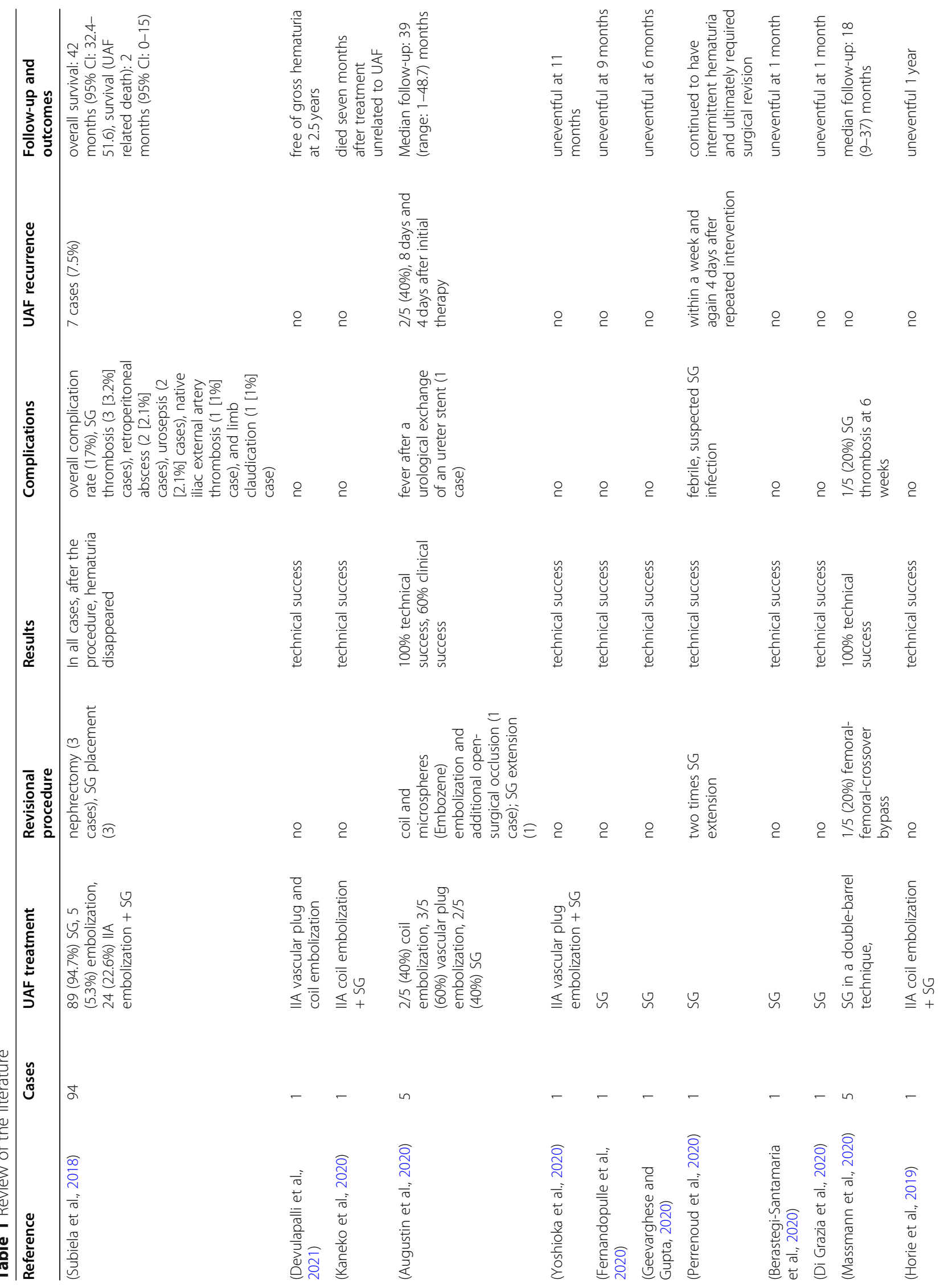




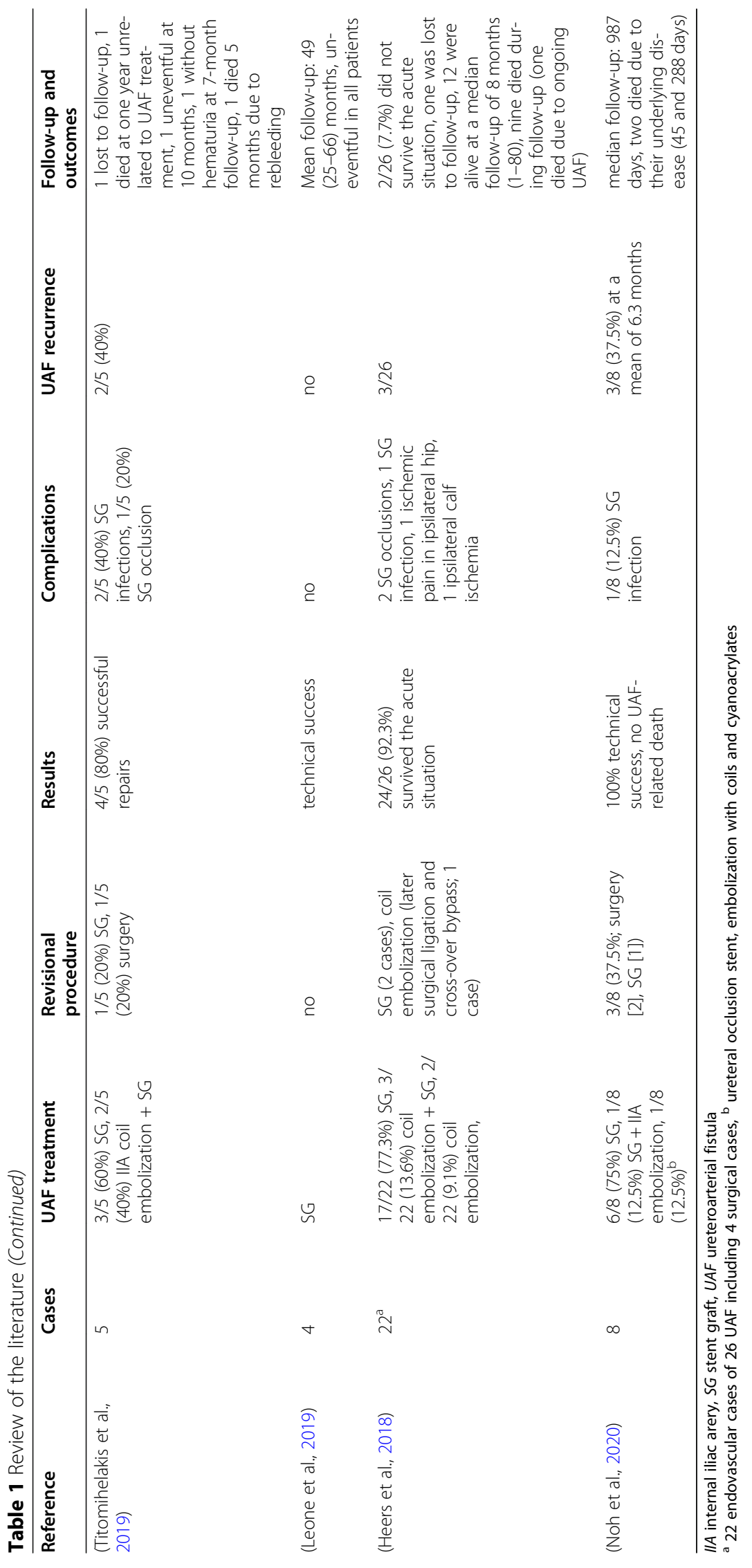



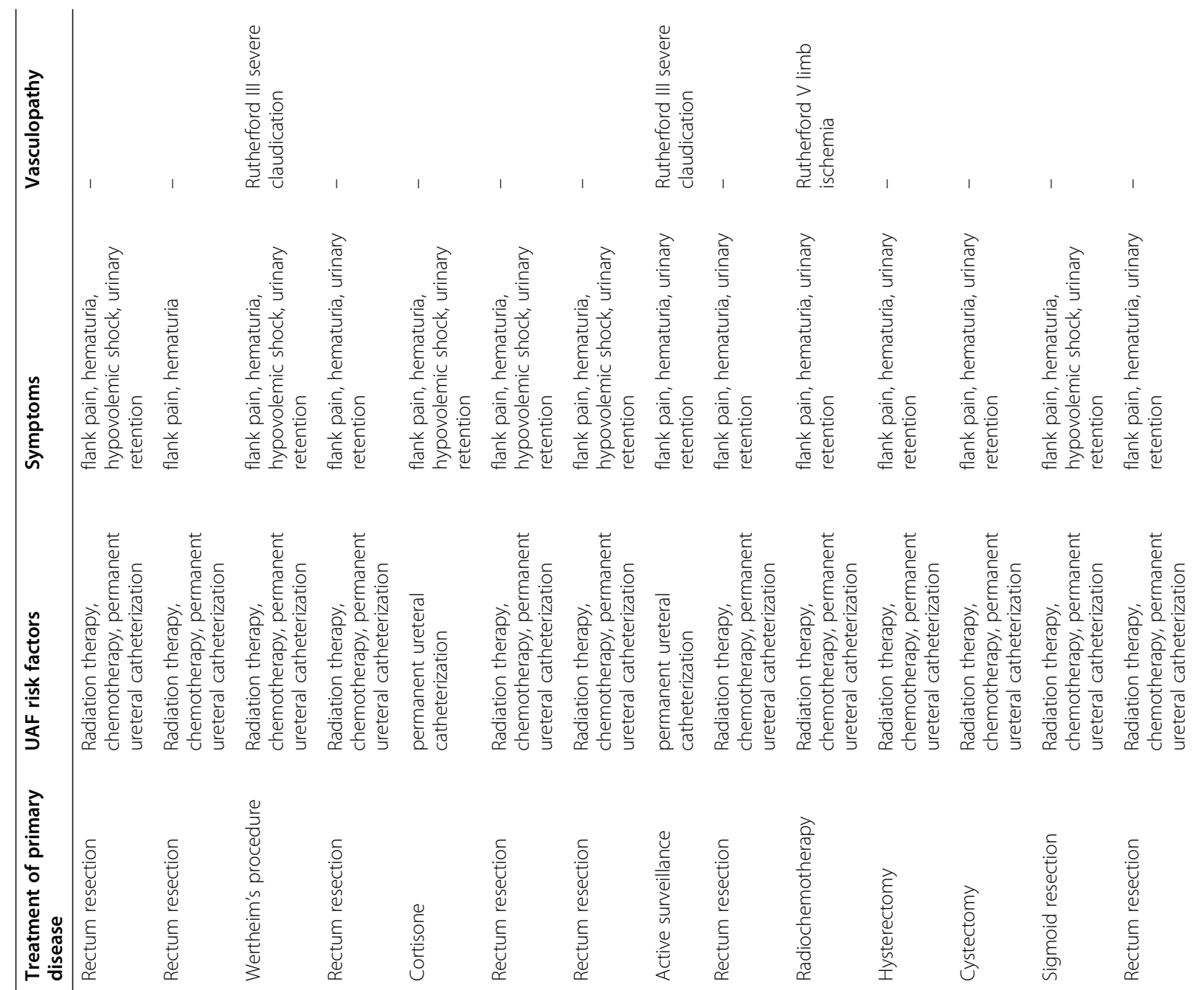

ֻั.

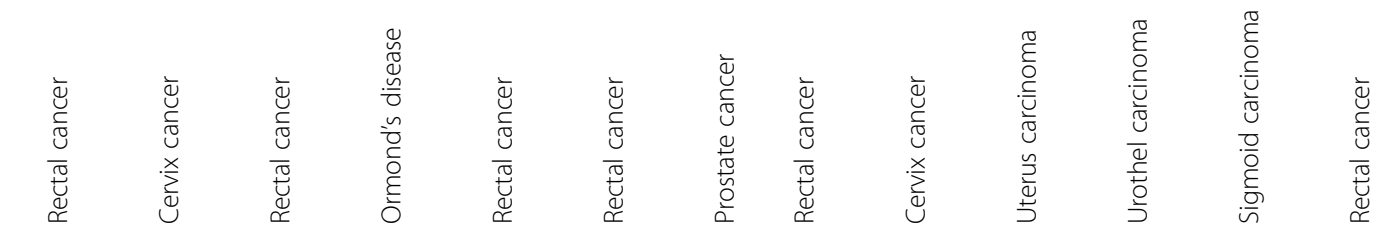

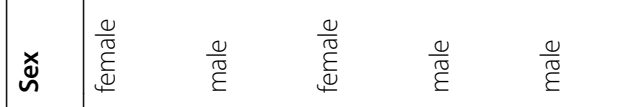

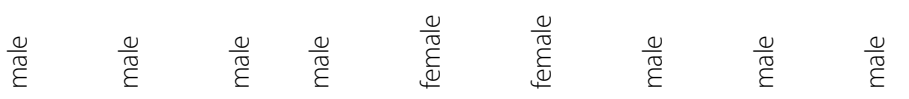

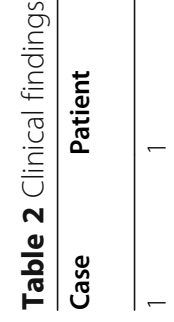

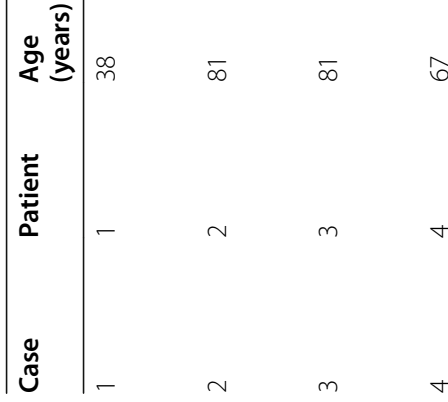




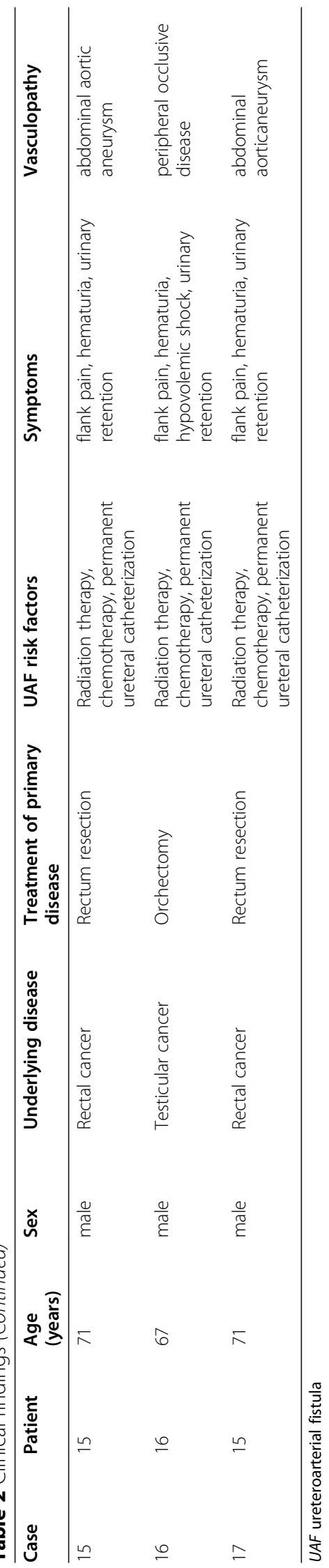


cases FemoSeal $^{\text {Tw }}$ (St. Jude Medical, Plymouth, MN, USA) was used, in 9 cases Perclose ProGlide (Abbott Vascular, Abbott Park, IL, USA) was applied, StarClose (Abbott Vascular, Abbott Park, IL, USA) was used twice and in one case Prostar XL (Abbott Vascular, Santa Clara, CA, USA) was employed. Diagnostic and technical data are shown in Table 3.

In our literature review SG placement with or without embolization was performed in 140 cases (92.1\%) while embolization alone was done in 12 cases (7.9\%).

\section{Outcomes}

Mean follow-up was 654 (range: 1-3269) days and four patients (23.5\%) were lost to follow-up between day one and 11 days. Among the remaining cases, no primary procedure-related deaths occurred during follow-up. Similarly, 30-day mortality rate was zero. All procedures were technically successful. During current hospital stay hematuria disappeared in $14 / 17$ cases (82.4\%). After a more extensive re-do intervention hematuria resolved in the remaining cases.
Recurrent hematuria happened in four cases, three of which occurred during the current hospital stay $(8,8$ and 13 days after initial treatment). Two could successfully be treated via secondary SG extension over the iliac crossing plus additional coil embolization of the IIA (case \#7 and \#11). In case \#16 where the fistula was located at the ureteral crossing of the aortofemoral bypass graft secondary coil embolization of the IIA alone was sufficient. There was one recurrent UAF related death 229 days after initial treatment (case \#3). In this patient, a re-opening of the fistula was found, caused by attempted interventional thrombectomy for critical limb ischemia. Periprocedural complications happened in two cases - in case \#3 the SG could not fully be unfolded and in case \#12 the Prostar XL system did not work after placement of a 14Fr-sheath which led to prolonged manual compression. SG thrombosis happened in 3 cases (1, 2 and 58 days after initial treatment). Two occlusions could have been managed via interventional thrombectomy with or without thrombolysis (case \#3 and case \#14). In case \#12 where the failed closure device led to immediate thrombosis the day after the

Table 3 Technical data and procedures

\begin{tabular}{|c|c|c|c|c|c|c|c|}
\hline Case & Patient & $\begin{array}{l}\text { Primary } \\
\text { radiological } \\
\text { diagnostics }\end{array}$ & Fistula location & UAF treatment & Stent data & Revisional procedure & $\begin{array}{l}\text { Medication } \\
\text { postinterventionally }\end{array}$ \\
\hline 1 & 1 & CECT & EIA & SG + IIA Coil embolization & 8/38 mm Advanta V12 & - & ASS100mg \\
\hline 2 & 2 & CECT & EIA & SG + IIA Coil embolization & 10/59 mm Advanta V12 & - & $\begin{array}{l}\text { ASS100mg + } 12 \text { weeks } \\
\text { Clopidogrel } 75 \mathrm{mg}\end{array}$ \\
\hline 3 & 3 & CECT & $\mathrm{ClA}$ & SG & $8 / 59 \mathrm{~mm}$ Advanta V12 & $\begin{array}{l}\text { Interventional } \\
\text { thrombectomy }\end{array}$ & $\begin{array}{l}\text { Oral anticoagulation }+12 \\
\text { weeks Clopidogrel } 75 \mathrm{mg}\end{array}$ \\
\hline 4 & 4 & CECT & $\| A$ & SG + IIA Coil embolization & 16/13/80 Endurant II & - & $\begin{array}{l}\text { ASS100mg + } 12 \text { weeks } \\
\text { Clopidogrel } 75 \mathrm{mg}\end{array}$ \\
\hline 5 & 5 & CECT & EIA & SG + IIA Coil embolization & 13.5/80 mm Fluency & - & $\begin{array}{l}\text { ASS100mg }+12 \text { weeks } \\
\text { Clopidogrel } 75 \mathrm{mg}\end{array}$ \\
\hline 6 & 6 & CECT & $\mathrm{ClA}$ & SG + IIA Coil embolization & 13.5/80 mm Fluency & - & $\begin{array}{l}\text { ASS100mg + } 12 \text { weeks } \\
\text { Clopidogrel } 75 \text { mg }\end{array}$ \\
\hline 7 & 7 & CECT & Obturator artery/IIA & SG & $\begin{array}{l}\text { 6/50 mm Viabahn; } \\
\text { 10/59 mm Advanta V12 }\end{array}$ & $\begin{array}{l}\mathrm{SG}+\| \mathrm{A} \text { Coil embolization } \\
\text { due to recurrent bleeding }\end{array}$ & $\begin{array}{l}\text { ASS100mg + } 12 \text { weeks } \\
\text { Clopidogrel } 75 \mathrm{mg}\end{array}$ \\
\hline 8 & 8 & UECT & $\mathrm{ClA}$ & SG + IIA Coil embolization & 10/59 mm Advanta V12 & - & ASS100mg \\
\hline 9 & 9 & UECT & $\mathrm{ClA}$ & SG & 16/12/70 mm Gore excluder; & - & ASS100mg \\
\hline 10 & 10 & CECT & $\mathrm{ClA}$ & SG & 7/50 mm Viabahn & - & ASS100mg \\
\hline 11 & 11 & UECT & $\mathrm{CIA}$ & SG & $\begin{array}{l}\text { 10/59 mm Advanta V12; } \\
\text { 13.5/80 mm Fluency }\end{array}$ & $\begin{array}{l}\mathrm{SG}+\| \mathrm{A} \text { Coil embolization } \\
\text { due to recurrent bleeding }\end{array}$ & ASS100mg \\
\hline 12 & 12 & UECT & $\mathrm{ClA}$ & SG & 11/100 mm Viabahn & Surgical thrombectomy & ASS100mg \\
\hline 13 & 13 & CECT & $\| \mathrm{A}$ & IIA Coil embolization & - & - & - \\
\hline 14 & 14 & $\mathrm{CECT}$ & $\mathrm{CIA}$ & SG & 6/38 mm Advanta V12 & $\begin{array}{l}\text { Interventional } \\
\text { thrombectomy and } \\
\text { thrombolysis }\end{array}$ & $\begin{array}{l}\text { ASS100mg }+12 \text { weeks } \\
\text { Clopidogrel } 75 \mathrm{mg}\end{array}$ \\
\hline 15 & 15 & Angiography & $\mathrm{CIA}$ & SG & $\begin{array}{l}\text { 16/12/70 mm Gore Excluder; } \\
\text { 16/14/120 mm Gore Excluder }\end{array}$ & $\begin{array}{l}\text { SG extension due to } \\
\text { aneurysm growth }\end{array}$ & ASS100mg \\
\hline 16 & 16 & Angiography & Aortofemoral Bypass & SG & 13.5/80 mm Fluency & $\begin{array}{l}\text { ॥A Coil embolization } \\
\text { due to recurrent bleeding }\end{array}$ & $\begin{array}{l}\text { ASS100mg + } 6 \text { weeks } \\
\text { Clopidogrel } 75 \text { mg }\end{array}$ \\
\hline 17 & 15 & Angiography & $\mathrm{ClA}$ & SG & 13.5/80 mm Fluency & - & ASS100mg \\
\hline
\end{tabular}

CECT contrast-enhanced computed tomography, CIA common iliac artery, IIA internal iliac artery, EIA external iliac artery, SG stent graft, UAF ureteroarterial fistula, UECT unenhanced computed tomography 
patient was transferred to surgical thrombectomy. Septicemia was found in 5 of 17 cases $(29.4 \%)$ at the point of intervention, in follow up there was no history of SG infections detected in those patients. During follow-up, one patient died of the underlying disease (576 days after the initial treatment). Early and long-term outcomes are summarized in Table 4.

Follow-up data varied substantially in our systematic literature review (Table 1). UAF recurrence (18/152, $11.8 \%)$, SG thrombosis $(7 / 140,5 \%)$ and SG infections (5/ $140,3.6 \%$ ) as main complications were observed (overall complications rate 13.8\%). The management of recurrent fistula was in 10 cases SG placement and in 10 cases open surgery. Two patients had embolization for UAF recurrence but finally needed surgical management, as well as one patient treated by SG extension. Five patients died related to UAF (3.3\%).

\section{Discussion}

To our knowledge we conduct the largest retrospective interventional radiological cohort study of cases with secondary UAFs from a single center.

The main symptom in our UAF patients was hematuria in all cases ranging from non-life-threatening transient hemorrhage to hypovolemic shock (in $41.2 \%$ of the cases). The need for blood transfusions and/or inotropic therapy is common. Flank pain and fever are further occurring as well (Heers et al., 2018).

Our diagnostic work up showed that in the minority of cases an active bleeding site could be located via CECT (2/10 cases; $20.0 \%)$ or angiography (3/17 cases; $17.7 \%)$. This confirms the findings of Guntau et al. with two detected UAFs in eight patients by CECT alone (Guntau et al., 2017). However, a negative CECT or angiogram does not rule out the diagnosis, therefore cystoscopy is used for confirmation of UAF and detecting the site of the fistula (Krambeck et al., 2005). Nevertheless, CECT proves to be crucial for planning the interventional approach, to locate the ureteral crossing and to rule out any other bleeding sites. Provocative angiography as an invasive imaging tool has been described as an effective procedure to demonstrate the active hemorrhage (Das et al., 2016; Fox et al., 2011; Guntau et al., 2017; van den Bergh et al., 2009). However, the risk of triggering extensive bleeding or to reopen a currently clotted fistula seems unnecessarily high. Positive CECT and angiography is shown in Fig. 1.

In the therapeutic management, there has been a paradigm shift from a surgical approach, which was still the standard of care in 2004, toward interventional angiography (Bergqvist et al., 2001; Fox et al., 2011; Madoff et al., 2004). Patients typically carry a high risk for complications due to previous extensive surgery and

Table 4 Outcomes

\begin{tabular}{|c|c|c|c|c|c|c|c|}
\hline Case & Patient & $\begin{array}{l}\text { Technical } \\
\text { success }\end{array}$ & $\begin{array}{l}\text { Early clinical } \\
\text { success }\end{array}$ & $\begin{array}{l}\text { Periprocedural } \\
\text { complication }\end{array}$ & Stent thrombosis (days) & $\begin{array}{l}\text { Recurrent bleeding } \\
\text { (days) }\end{array}$ & Follow-up data \\
\hline 1 & 1 & yes & yes & - & no & no & uneventful at 4 days \\
\hline 2 & 2 & yes & yes & - & no & no & uneventful at 1 days \\
\hline 3 & 3 & yes & yes & Not fully unfolded stent & yes (2) & yes (229) & $\begin{array}{l}\text { death at } 229 \text { days due } \\
\text { to recurrent hemorrhage }\end{array}$ \\
\hline 4 & 4 & yes & yes & - & no & no & uneventful at 3 days \\
\hline 5 & 5 & yes & yes & - & no & no & uneventful at 69 days \\
\hline 6 & 6 & yes & yes & - & no & no & uneventful at 186 days \\
\hline 7 & 7 & yes & no & - & no & yes (8) & alive at 11 days \\
\hline 8 & 8 & yes & yes & - & no & no & uneventful at 1390 days \\
\hline 9 & 9 & yes & yes & - & no & no & uneventful at 846 days \\
\hline 10 & 10 & yes & yes & - & no & no & uneventful at 1237 days \\
\hline 11 & 11 & yes & no & - & no & yes (13) & alive at 763 days \\
\hline 12 & 12 & yes & yes & Closure device failure & yes (1) & no & alive at 220 days \\
\hline 13 & 13 & yes & yes & - & no & no & uneventful at 1984 days \\
\hline 14 & 14 & yes & yes & - & yes (58) & no & alive at 3269 days \\
\hline 15 & 15 & yes & yes & - & no & no & alive at 187 days \\
\hline 16 & 16 & yes & no & - & no & yes (8) & $\begin{array}{l}\text { death at } 576 \text { days due } \\
\text { to underlying disease }\end{array}$ \\
\hline 17 & 15 & yes & yes & - & no & no & alive at 147 days \\
\hline Total (\%) & & 17 (100\%) & 14 (82.4\%) & $2(11.8 \%)$ & $3(17.7 \%)$ & $4(23.5 \%)$ & $\begin{array}{l}\text { Mean follow-up } 654 \\
\text { (Range: 1-1984) days }\end{array}$ \\
\hline
\end{tabular}




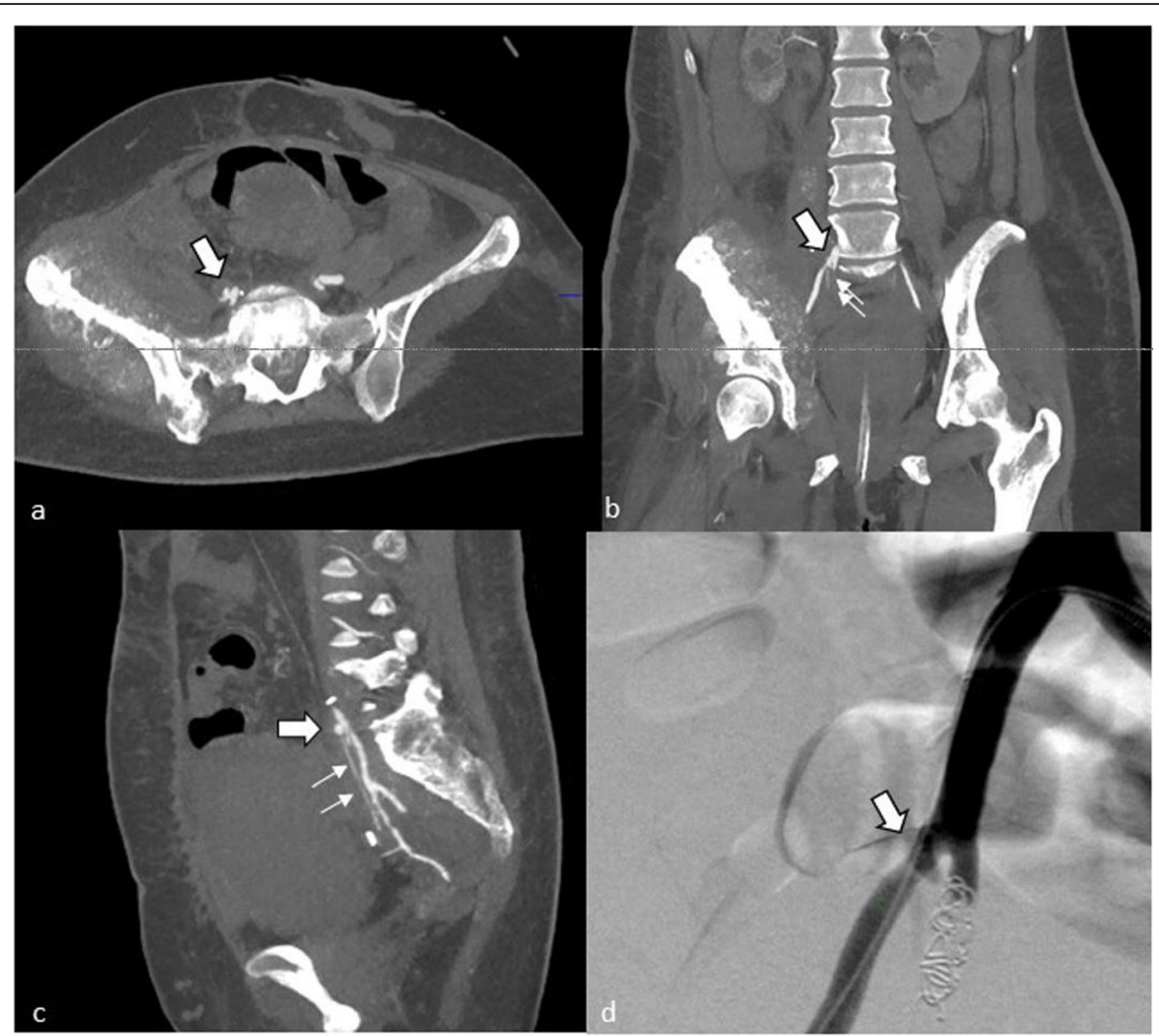

Fig. 1 Case \#1: Contrast enhanced computed tomography confirmed the ureteroarterial fistula (large arrows) and demonstrated even extravasation into the right ureter (small arrows) (a, b, c). Angiography shows a defect at the iliac junction (large arrow). Coil embolization of the internal iliac artery has already been performed (d)

radiation therapy which lead to adhesions, fibrosis, and frail tissue (Heers et al., 2018). In patients with UAF to the IIA only, arterial coil embolization can be considered. Most of the UAF involve EIA or CIA, so covered stent treatment is necessary (Muraoka et al., 2006; van den Bergh et al., 2009). SG treatment is less invasive than open surgery and offers rapid bleeding control (Patel et al., 2014).

Endovascular therapy offers high technical and early clinical success rates (100\% and $82.4 \%$ in our cohort). Our literature review revealed nearly 100\% technical success rates through all studies (Table 1). The large patient series of 94 UAF by Subiela et al. shows disappearance of hematuria in all cases after the procedure (Subiela et al., 2018). Severe complications like SG occlusions or SG infections are rare (Malgor et al., 2012; Okada et al., 2013). Stent thrombosis is one important postinterventional complication: In our cohort we observed SG thrombosis in $17.7 \%$ of the cases in opposition to $5 \%$ in our literature review. In our experience major risk factors for developing stent thrombosis were underlying vasculopathy or advanced tumor disease with extrinsic stenosis of iliac vessels since all three patients who developed SG thrombosis had a history of pelvic malignancy with previous surgery and radiotherapy, one of them also had advanced peripheral artery disease. Massmann et al. found stent thrombosis in their case series (1/5 cases, $20 \%)$ probably caused by pre-existing large tumor vessel invasion and small vessel diameters (Massmann et al., 2020). Although we would primarily suggest an endovascular thrombectomy attempt for SG thrombosis, our series and the experience of Massmann et al. show interventional and surgical thrombectomy both to be suitable options (Massmann et al., 2020). Too maintain the risk for SG occlusions as low as possible patients should be put on single anti platelet therapy after the procedure. Periprocedural complications can be decreased by using suitable equipment, like closure devices after the use of larger sheaths. One SG thrombosis in our cohort happened due to device failure which led to prolonged manual compression and stent occlusion the day after. Literature already disclosed controversies after use of Prostar XL (Maniotis et al., 2017; Power et al., 2019).

In spite of a high number of reported urinary tract infections which sometimes lead to septicemia in these patients, the risk of secondary SG infections seems to be overrated (Darcy, 2009). In the current study none of 
our patients suffered from morbidity due to SG infections during their postinterventional course. In our literature research we found 5 infections of 140 implanted SG (3.6\%). This matches previously published experience (Malgor et al., 2012). Since all our patients carried ureteral stents, we found no patient without bacterial colonization, so antibiotic treatment based on urine cultures and resistance profiles is mandatory. SG placement in an infectious site is still critical. Nevertheless, UAF typically requires urgent treatment. Although there is no established consensus, it is recommended that these patients receive perioperative antibiotic treatment (Hong et al., 2016). Titomihelakis et al. suggest antibiotics for 6 weeks after the procedure, and in most cases lifelong antibiotics may not be unreasonable. Taking the patient's medical condition into account, removal of the infected foreign body might be suitable (Titomihelakis et al., 2019).

In the current series, recurrent bleedings developed after insufficient coverage of the fistula during the initial intervention and were manageable by a secondary treatment. None of these patients received secondary surgical treatment for recurrent hemorrhage. Additional risk factors included complex underlying situations with severe vasculopathy or stenosing tumor burden. Following our experience, we suggest to cover the ureteral crossing from the CIA to the EIA by a SG with prior coil embolization of the IIA. IIA coil embolization prevents retrograde perfusion of the UAF through the gluteal arteries, but also lowers the risk of recurrent bleedings eg., in cases of fistulas from the proximal IIA.
Embolization of the IIA alone would not be sufficient for UAF treatment (Massmann et al., 2020). It is crucial to detect fistula recurrence. In our series recurrent hematuria happened in $4 / 17$ cases $(23.5 \%)$, one of them died due to recurrence of the UAF (5.9\%). Three recurrent fistulas could successfully be treated in a revisional endovascular procedure. Our literature review found a fistula recurrence rate of $11.8 \%$ and five UAF related deaths (3.3\%). Guntau et al. identified recurrent hematuria in one of eight patients (12.5\%). This patient could also successfully be treated with a secondary endovascular treatment, a combination of mild dilatation of the native iliac artery and a short distal landing zone seemed to be the cause (Guntau et al., 2017). Van den Bergh et al. found in their review of various procedures for the treatment of UAF a recurrent fistula related mortality of 18 out of 139 patients (13\%) (van den Bergh et al., 2009). In our cohort one patient died due to recurrent hemorrhage 229 days after initial treatment. This patient had a large pelvic tumor mass which led to external compression and consecutive stenosis of the iliac vessels. The inserted SG unfolded incompletely during the initial procedure and SG thrombosis occurred during the postinterventional course. This led to a secondary procedure to treat acute lower limb ischemia, which resulted in reopening of the UAF with consequent bleeding (Fig. 2). Even if open surgery can become necessary in some UAF patients, endovascular approach should be evaluated as first approach. Studies have shown the long term effectiveness of endovascular treatment. Although, reasons for fistula recurrence have been poorly reported

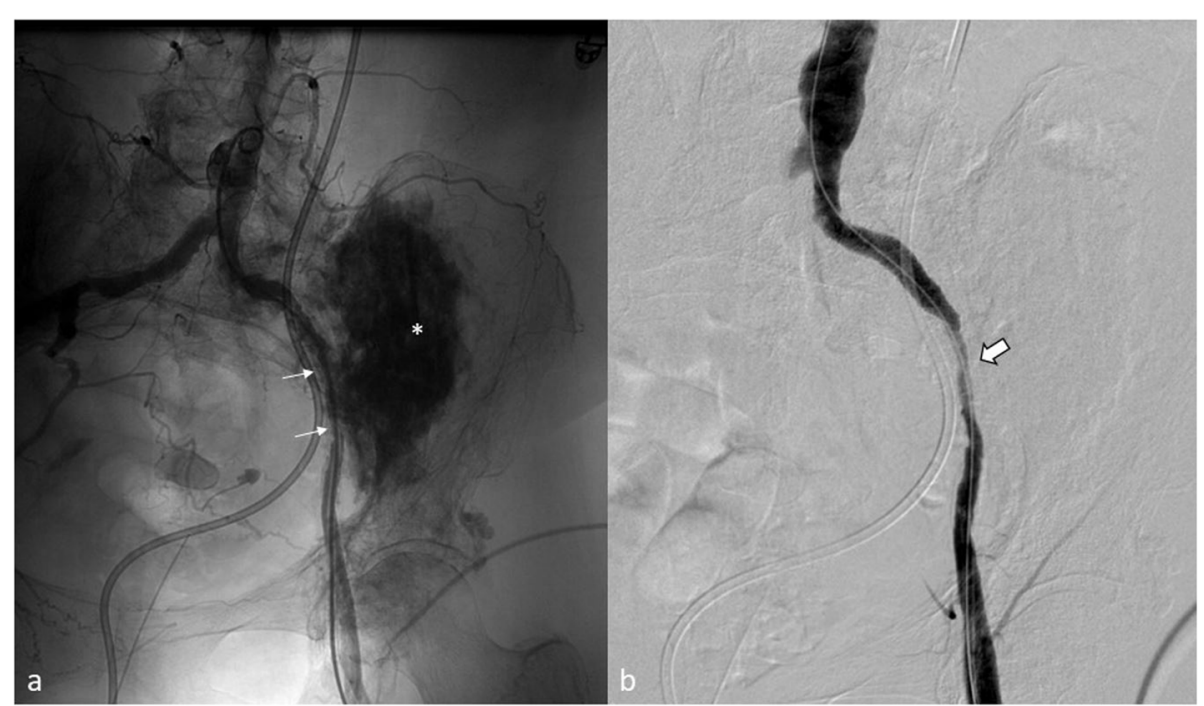

Fig. 2 Case \#3: 81-year-old woman with left sided bleeding from UAF. Angiogram shows the ureteric stent in direct proximity of the left CIA and EIA with closed IIA while there is no direct proof of the fistula on angiography. Massive calcified bone metastasis $\left(^{*}\right)$ compresses the left iliac arteries (small arrows) (a). The final control angiogram shows the crossing of the common iliac artery and the ureteric stent covered by a stent graft. Metastatic compression led to a not fully unfolded stent graft (large arrow) (b) 
(Bilbao et al., 2005; Subiela et al., 2018; van den Bergh et al., 2009). Noh et al. found in their patients infection, pseudaneurysm formation at the SG edge, and persistent irritation by a pre-existing artificial intervertebral disc predisposing factors for recurrence (Noh et al., 2020). Type 1 endoleak by not fully covering stent edges also seems a risk factor (Perrenoud et al., 2020).

Our study is limited by its retrospective nature and by the small number of cases. In addition, follow-up periods varied substantially.

\section{Conclusions}

In view of the low incidence of this disease and continuously evolving diagnostic and therapeutic tools, it seems difficult to establish evidence-based recommendations for these patients. Nevertheless, both urologists and interventional radiologists seem to be well aware of the special features of this rare disease. Endovascular therapy offers high technical success and rapid bleeding control rates. Severe complications like SG occlusions or SG infections are rare but maintain a problem. Since nearly all patients carry ureteral stents, antibiotic treatment based on urine cultures and resistance profiles is mandatory. Based on the patient's medical condition explantation of an infected SG can be considered. Too maintain the risk for SG occlusions as low as possible patients should be put on single anti platelet therapy. If SG thrombosis has occured, both interventional and surgical thrombectomy are well suited options.

In conclusion, endovascular therapy for UAF is a safe and effective treatment option to prevent acute hemorrhage-related death. Since UAF recurrence often results in fatal hemorrhage close and long follow-up is crucial to timely perform additional treatments if necessary.

\section{Abbreviations}

CECT: Contrast-enhanced computed tomography; CIA: Common iliac artery; EIA: External iliac artery; Fr: French; IIA: Internal iliac artery; SG: Stent graft; UAF: Ureteroarterial fistula; UECT: Unenhanced computed tomography

\section{Acknowledgements}

Not applicable.

\section{Authors' contributions}

BS: Conceptualization, Methodology, Data Curation, Writing. JN: Review \& Editing. MS: Supervision, Review \& Editing. SH: Review \& Editing. FB: Supervision, Review \& Editing. LM: Conceptualization \& Supervision. The authors read and approved the final manuscript.

\section{Funding}

This study was not supported by any funding. Open Access funding enabled and organized by Projekt DEAL.

\section{Availability of data and materials}

All data generated or analysed during this study are included in this published article.

\section{Declarations}

Ethics approval and consent to participate

All procedures performed in studies involving human participants were in accordance with the ethical standards by the institutional review board of the University of Freiburg (\#368/20).and with the 1964 Helsinki declaration and its later amendments. Informed consent was waived due to our analysis' retrospective nature.

Consent for publication

Not applicable.

\section{Competing interests}

BS is holding stocks of Medtronic plc. The other authors declare that they have no conflict of interest.

\section{Author details}

'Department of Radiology, Medical Center - University of Freiburg, Faculty of Medicine, University of Freiburg, Freiburg, Germany. ${ }^{2}$ Department of Urology, Medical Center - University of Freiburg, Faculty of Medicine, University of Freiburg, Freiburg, Germany. ${ }^{3}$ Diagnostic Radiology, Pediatric Radiology and Interventional Radiology, St.-Josefs-Krankenhaus, Freiburg, Germany.

Received: 24 February 2021 Accepted: 6 April 2021

Published online: 17 April 2021

\section{References}

Augustin AM, Torre GD, Kocot A, Bley TA, Kalogirou C, Kickuth R (2020) Endovascular therapy of arterioureteral fistulas. Vasa:1-9. https://doi.org/10.1 024/0301-1526/a000922

Berastegi-Santamaria C, Echevarria-Uraga JJ, Garcia-Garai N, Jiménez-Zapater C, Cura-Allende GD (2020) Ureteroarterial fistula treated by endovascular stent placement. Radiol Case Rep 15(9):1714-1717. https://doi.org/10.1016/j.radcr.2 020.05.044

Bergqvist D, Pärsson H, Sherif A (2001) Arterio-ureteral Fistula - a Systematic Review. Eur J Vasc Endovasc Surg 22(3):191-196. https://doi.org/10.1053/ ejvs.2001.1432

Bilbao Jl, Cosín O, Bastarrika G, Rosell D, Zudaire J, Martínez-Cuesta A (2005) Treatment of Ureteroarterial fistulae with covered vascular Endoprostheses and ureteral occlusion. Cardiovasc Intervent Radiol 28(2):159-163. https://doi. org/10.1007/s00270-004-0196-0

Darcy M (2009) Uretro-Arterial Fistulas. Tech Vasc Interv Radiol 12(3):216-221. https://doi.org/10.1053/j.tvir.2009.09.005

Das A, Lewandoski P, Laganosky D, Walton J, Shenot P (2016) Ureteroarterial fistula: a review of the literature. Vascular 24(2):203-207. https://doi.org/10.11 $77 / 1708538115585261$

Devulapalli KK, Lang PY, Stewart JK (2021) Ureteroarterial fistula embolization by transradial approach: a case report. Radiol Case Rep 16(4):968-970. https:// doi.org/10.1016/j.radcr.2021.02.004

Di Grazia E, La Malfa T, Gasso G (2020) Ureteral iliac artery fistula in idiopathic retroperitoneal fibrosis: a case report. Arch Ital Urol Androl 92(2). https://doi. org/10.4081/aiua.2020.2.107

Fernandopulle CL, Jeyaraj R, Alchanan R, Huang DY (2020) Ureteroarterial fistula: imaging diagnosis and endovascular management. BMJ Case Rep 13(9): e236011. https://doi.org/10.1136/bcr-2020-236011

Fox JA, Krambeck A, McPhail EF, Lightner D (2011) Ureteroarterial fistula treatment with open surgery versus endovascular management: long-term outcomes. J Urol 185(3):945-950. https://doi.org/10.1016/j.juro.2010.10.062

Geevarghese R, Gupta N (2020) Successful endovascular Management of an Arterioureteral Fistula Presenting with massive hematuria in a failed renal transplant. J Endourol Case Rep 6(2):73-76. https://doi.org/10.1089/cren.2019. 0095

Guntau M, Hegele A, Rheinheimer S, Hofmann R, Mahnken AH (2017) Balloonexpandable stent graft for treating Uretero-iliac artery fistula. Cardiovasc Intervent Radiol 40(6):831-835. https://doi.org/10.1007/s00270-017-1586-4

Heers H, Netsch C, Wilhelm K, Secker A, Kurtz F, Spachmann P, Viniol S, Hofmann $R$, Hegele A (2018) Diagnosis, treatment, and outcome of Arterioureteral fistula: the Urologist's perspective. J Endourol 32(3):245-251. https://doi.org/1 0.1089/end.2017.0819 
Hong S-Y, Noh M, Ko G-Y, Han Y, Kwon H, Kwon T-W, Cho Y-P (2016) Management strategy for ureteral-iliac artery fistula. Ann Vasc Surg 36:22-27. https://doi.org/10.1016/j.avsg.2016.02.033

Horie K, Fujiwara T, Satoyoshi K, Munehisa M, Inoue N (2019) Endovascular treatment of ureteroarterial fistula using a covered stent, evaluated by intravascular ultrasound: a case report. CVIR Endovasc 2(1):16. https://doi. org/10.1186/s42155-019-0060-6

Kaneko T, Sakamoto A, Yamada Y, Yamamoto M, Kondo H, Nakagawa T (2020) Uretero-arterial fistula treated with endovascular stent graft following multiple interventions. IJU Case Reports 3(6):275-277. https://doi.org/10.1002/ iju5.12216

Krambeck AE, DiMarco DS, Gettman MT, Segura JW (2005) Ureteroiliac artery fistula: diagnosis and treatment algorithm. Urology 66(5):990-994. https://doi. org/10.1016/j.urology.2005.05.036

Leone L, Scarcella S, Dell'Atti L, Tiroli M, Sternardi F, Galosi AB (2019) Uretero-iliac artery fistula: a challenge diagnosis for a life-threatening condition: monocentric experience and review of the literature. Int Urol Nephrol 51(5): 789-793. https://doi.org/10.1007/s11255-019-02097-2

Luther B, von Lilien-Waldau V, Mamopoulos A, Katoh M, Friedrich M, Weinknecht S, Lent V (2014) Die uretero-arterielle Fistel - Ursachen, Diagnostik und Therapieergebnisse. Aktuel Urol 45(03):204-208. https://doi.org/10.1055/s0034-1376953

Madoff DC, Gupta S, Toombs BD, Skolkin MD, Charnsangavej C, Morello FA, Ahrar K, Hicks ME (2004) Arterioureteral fistulas: a clinical, diagnostic, and therapeutic dilemma. AJR Am J Roentgenol 182(5):1241-1250. https://doi. org/10.2214/ajr.182.5.1821241

Malgor RD, Oderich GS, Andrews JC, McKusick M, Kalra M, Misra S, Gloviczki P, Bower TC (2012) Evolution from open surgical to endovascular treatment of ureteral-iliac artery fistula. J Vasc Surg 55(4):1072-1080. https://doi.org/10.101 6/j.jvs.2011.11.043

Maniotis C, Andreou C, Karalis I, Koutouzi G, Agelaki M, Koutouzis M (2017) A systematic review on the safety of Prostar $\mathrm{XL}$ versus ProGlide after TAVR and EVAR. Cardiovasc Revasc Med 18(2):145-150. https://doi.org/10.1016/j.carrev.2 016.11 .004

Massmann A, Fries P, Shayesteh-Kheslat R, Buecker A, Stöckle M, Niklas C (2020) Life-threatening arterioureteral fistula treatment by endovascular complete anatomic iliac artery bifurcation reconstruction. J Vasc Surg Cases Innov Tech 6(2):199-204. https://doi.org/10.1016/j.jvscit.2020.01.012

Moschcowitz AV (1908) Simultaneous ligation of both external iliac arteries for secondary hemorrhage following bilateral ureterolithotomy. Ann Surg 48(6): 872-875. https://doi.org/10.1097/00000658-190812000-00009

Muraoka N, Sakai T, Kimura H, Kosaka N, Itoh H, Tanase K, Yokoyama O (2006) Endovascular treatment for an iliac artery-ureteral fistula with a covered stent. J Vasc Interv Radiol 17(10):1681-1685. https://doi.org/10.1097/01.RVI. 0000236713.46897 .05

Noh SY, Shin JH, Yang WJ, Chu HH, Park S, Chen C, Lee WH (2020) Arterioureteral fistula: overview of clinical characteristics, endovascular management, and outcomes. Minimal Invasive Ther Allied Technol:1-9. https://doi.org/10.1 080/13645706.2020.1782939

Okada T, Yamaguchi M, Muradi A, Nomura Y, Uotani K, Idoguchi K, Miyamoto N, Kawasaki R, Taniguchi T, Okita Y, Sugimoto K (2013) Long-term results of endovascular stent graft placement of Ureteroarterial fistula. Cardiovasc Intervent Radiol 36(4):950-956. https://doi.org/10.1007/s00270-012-0534-6

Patel D, Kumar A, Ranganath P, Contractor S (2014) Endovascular treatment of arterio-ureteral fistulae with covered stents: case series and review of the literature. SAGE Open Med Case Rep 2:2050313X1454809. https://doi.org/1 $0.1177 / 2050313 \times 14548094$

Perrenoud AL, Heiberger G, Shriver J, Yim D (2020) Endoleak and Pseudoaneurysm formation in the setting of stent graft infection following endovascular Uretero-arterial fistula repair: the dreaded complication. Cureus 12:e8830. https://doi.org/10.7759/cureus.8830

Pillai AK, Anderson ME, Reddick MA, Sutphin PD, Kalva SP (2015) Ureteroarteria fistula: diagnosis and management. Am J Roentgenol 204(5):W592-W598. https://doi.org/10.2214/AJR.14.13405

Power D, Schäfer U, Guedeney P, Claessen BE, Sartori S, Sorrentino S, Lefèvre T, Kupatt C, Tchetche D, Dumonteil N, Webb JG, Colombo A, Windecker S, Berg JM, Hildick-Smith D, Boekstegers P, Linke A, Tron C, Van Belle E, Asgar AW, Jeger R, Sardella G, Hink U, Husser O, Grube E, Lechthaler I, Wijngaard P, Anthopoulos P, Deliargyris EN, Bernstein D, Hengstenberg C, Mehran R, Dangas GD (2019) Impact of percutaneous closure device type on vascular and bleeding complications after TAVR: a post hoc analysis from the BRAVO-
3 randomized trial. Catheter Cardiovasc Interv 93:1374-1381. https://doi.org/1 $0.1002 /$ ccd.28295

Subiela JD, Balla A, Bollo J, Dilme JF, Soto Carricas B, Targarona EM, RodriguezFaba O, Breda A, Palou J (2018) Endovascular Management of Ureteroarterial Fistula: single institution experience and systematic literature review. Vasc Endovasc Surg 52(4):275-286. https://doi.org/10.1177/1538574418761721

Titomihelakis G, Feghali A, Nguyen T, Salvatore D, DiMuzio P, Abai B (2019) Endovascular management and the risk of late failure in the treatment of ureteroarterial fistulas. J Vasc Surg Cases Innov Tech 5(4):396-401. https://doi. org/10.1016/j.jvscit.2019.06.010

van den Bergh RCN, Moll FL, de Vries J-PPM, Lock TMTW (2009) Arterioureteral fistulas: unusual suspects-systematic review of 139 cases. Urology 74(2): 251-255. https://doi.org/10.1016/j.urology.2008.12.011

Yoshioka N, Takagi K, Morita Y, Kawase M, Morishima I (2020) Endovascular treatment of arterio-ureteral fistula with new-generation balloon-expandable stent graft using a 7-French system. SAGE Open Med Case Rep 8: 2050313X2095921. https://doi.org/10.1177/2050313X20959219

\section{Publisher's Note}

Springer Nature remains neutral with regard to jurisdictional claims in published maps and institutional affiliations.

\section{Submit your manuscript to a SpringerOpen ${ }^{\circ}$ journal and benefit from:}

- Convenient online submission

- Rigorous peer review

- Open access: articles freely available online

- High visibility within the field

- Retaining the copyright to your article

Submit your next manuscript at $\boldsymbol{\sim}$ springeropen.com 